\title{
Clinical Isolates of Acinetobacter baumannii From Tehran Hospitals: Pulsed-field Gel Electrophoresis Characterization, Clonal Lineages, Antibiotic Susceptibility, and Biofilm-forming Ability
}

\author{
Mahdi Akbari Dehbalaei, ${ }^{1}$ Shahin Najar-Peerayeh,, ${ }^{1,}$ Morovat Taherikalani, ${ }^{2}$ and Mehrdad Behmanesh ${ }^{3}$ \\ ${ }^{1}$ Department of Bacteriology, Faculty of Medical Sciences, Tarbiat Modares University, Tehran, Iran \\ ${ }^{2}$ Razi Herbal Medicines Research Center, Department of Microbiology, School of Medicine, Lorestan University of Medical Sciences, Khorramabad, Iran \\ ${ }^{3}$ Department of Genetics, Faculty of Biological Sciences, Tarbiat Modares University, Tehran, IR Iran \\ "Corresponding author: Shahin Najar-Peerayeh, Department of Bacteriology, Faculty of Medical Sciences, Tarbiat Modares University, Tehran, Iran. E-mail \\ najarp_s@modares.ac.ir
}

Received 2017 January 03; Revised 2017 March 09; Accepted 2017 March 18.

\begin{abstract}
Background: Acinetobacter baumannii is known as a potential pathogen in hospitals and is responsible for the dramatic increase in carbapenem resistance in Iran in the recent years.

Objectives: The current study aimed at determining the genetic association of the isolates by the pulsed-field gel electrophoresis (PFGE) technique, identify international clones, evaluate biofilm formation ability and its relationship with antibiotic resistance. Methods: In the current study, a total of 48 A. baumannii isolates were collected from 2 hospitals in Tehran, Iran, from 2010 to 2012. Isolates were subjected to antimicrobial susceptibility testing, determination of carbapenemase encoding genes, biofilm formation, and genetic relationships analysis.

Results: The obtained results demonstrated that the rate of resistance to carbapenem, meropenem, imipenem, and doripenem was $76 \%$. The carbapenemase-encoding gene $b l a_{\text {OXA-23-like }}$ was found in 32 isolates, while $b l a_{\text {OXA-40-like }}\left(b_{l} a_{O X A-24-l i k e}\right.$ ), bla $a_{\text {OXA-58-like }}$, bla $a_{\text {VIM-type }}$ and bla $_{\text {IMP-type }}$ were found in $11,1,19$. and 5 isolates, respectively. When the lineage of the isolates was evaluated by the multiplex polymerase chain reaction (PCR), it was found that 28 isolates belonged to group 1 and 8 isolates to group 2 . None of the isolates belonged to group 3. Twelve isolates could not be typed by this method. The study findings interestingly demonstrated that 13 isolates showed no biofilm formation. Data of biofilm formation also demonstrated that 28,4 , and 3 remaining isolates had weak, moderate, and strong biofilm formation, respectively. The pulsed field gel electrophoresis result revealed 11 unique clones.

Conclusions: International clone 1 was the most commonly identified clone in the current study. This clone was mostly associated with $b l a_{O X A-23-l i k e}$ gene; therefore, $64 \%$ of the isolates in this clone possessed bla OXA-23-like gene.
\end{abstract}

Keywords: Acinetobacter baumannii, Electrophoresis, Gel, Pulsed-Field, Biofilm

\section{Background}

Acinetobacter baumannii emerged as a highly troublesome pathogen for many institutions globally (1). Outbreaks of infections due to this organism are reported in neonatal intensive care units (NICUs) (2), medical and surgical wards, burn units, and are also associated with medical equipment and hands of personnel (3). The rate of antibiotic resistance is high (4). Multidrug-resistant (MDR) A. baumannii is frequently reported as endemic in certain hospital wards and responsible for numerous nosocomial outbreaks worldwide $(4,5)$. Metallo-betalactamases (MBLs) and oxacillinases (OXAs) are the 2 main groups of carbapenemases in A. baumannii. OXA-type betalactamases are responsible for the most common type of carbapenem resistance via enzymatic degradation (6). Although MBLs are not the predominant carbapenemases in A. baumannii, VIM, IMP, SIM, and NDM metallo-beta- lactamases contribute to the high-level resistance to carbapenems (7).

Infections can have serious repercussions for patient morbidity and mortality. Patients can acquire the infection from environmental sources or from other patients (8). Acinetobacter spp. frequently causes infections associated with medical devices. Biofilm formation is a wellknown pathogenic mechanism in such infections (1). Various typing methods are employed in the epidemiological investigation of outbreaks due to Acinetobacter species. The most widely applied methods focus on variations in the phenotypic properties such as antimicrobial susceptibility, biotypes, serotypes, phage types, or cell envelope protein profiles (9). Many of these traditional typing procedures have insufficient reproducibility, type ability, and discriminatory power.

Molecular techniques such as plasmid typing, ribotyping, and analysis of genomic DNA by pulsed-field gel elec- 
trophoresis (PFGE) and by arbitrarily primed polymerase chain reaction (PCR), which directly compare variations in the DNA of bacterial isolates, are applied to epidemiological investigations of Acinetobacter isolates $(10,11)$.

\section{Objectives}

The current study aimed at determining the susceptibility rate, PFGE characterization, clonal lineages, and biofilm formation in the clinical isolates of $A$. baumannii in Tehran hospitals, Iran.

\section{Methods}

\subsection{Sample Collection and Bacterial Identification}

A total of 48 clinical samples were collected from wound, trachea, urine, catheter, sputum, and burn from patients admitted to Tehran hospitals from 2010 to 2012. The isolates were identified as A. baumannii according to the analytical profile $b l a_{O X A-51-l i k e}$ index 20NE protocol (BioMerieux, France) and genetically confirmed by the presence of gene (12). Then, the isolates were stored at $-70^{\circ} \mathrm{C}$ in nutrient broth plus 30\% glycerol.

\subsection{Antibiotic Susceptibility Testing}

Antibiotic susceptibility was determined by disk diffusion method on Mueller-Hinton agar (Merck, Germany) according to the clinical and laboratory standards institute (CLSI) guidelines for the following antimicrobial agents: imipenem $(10 \mu \mathrm{g})$, meropenem $(10 \mu \mathrm{g})$, doripenem $(10 \mu \mathrm{g})$, piperacillin $(100 \mu \mathrm{g})$, gentamicin $(10 \mu \mathrm{g})$, amikacin (30 $\mu \mathrm{g})$, ciprofloxacin $(5 \mu \mathrm{g})$, minocycline $(30 \mu \mathrm{g})$, doxycycline $(30 \mu \mathrm{g})$, and piperacillin-tazobactam $(100 / 10 \mu \mathrm{g})$ (Mast Diagnostics, UK). Escherichia coli ATCC 25922, Escherichia coli ATCC 35218, and also Pseudomonas aeruginosa ATCC 27853 were used as controls (13).

\subsection{PCR for Carbapenemase Genes}

Genomic DNA was extracted using the boiling method. PCR was employed to detect $b l a_{O X A-51-l i k e}$, the A. baumanniispecific-gene) Table 1. (Isolates were also screened for the other major groups that confer resistance to carbapenems; ie, bla OXA-23-like, bla OXA-40-like $\left(b a_{\text {OXA-24-like }}\right)$, and bla OXA-58-like by multiplex reaction as well as the $b l a_{\text {NDM-type }}, b l a_{\text {SIM-type }}$, bla $_{\text {IMP-type }}$, and bla $a_{V I M-t y p e}$ by single PCR (TAG Copenhagenard, Denmark) (14) (Table 1). The PCR products were separated by $1 \%$ agarose gel electrophoresis stained with neutral red (Sigma Aldrich, Germany) and visualized under ultraviolet (UV) light.

\subsection{Biofilm Formation}

Biofilm formation was quantified by the microtiter plate assay method as described previously (15). Briefly, A. baumannii species were grown overnight in trypticase soy broth (TSB) (Merck, Germany) with $0.25 \%$ glucose at $37^{\circ} \mathrm{C}$. The culture was diluted 1:50 in (TSB). Then, $200 \mathrm{~mL}$ of suspension was used to inoculate wells of sterile 96well polystyrene microtiter plates, followed by incubation at $37^{\circ} \mathrm{C}$ for 72 hours. After 3 washes with phosphate buffered saline (PBS), any remaining biofilm was stained with crystal violet $1 \%(\mathrm{w} / \mathrm{v})$ for 25 minutes and wells were washed again with PBS. The dye bound to the adherent cells was re-solubilized with $200 \mathrm{~mL}$ of ethanol/acetone (80:20, $\mathrm{V} / \mathrm{V}$ ) and the optical density (OD) was quantified at 570 $n m$ using an enzyme-linked immunosorbent assay (ELISA) reader. Each assay was performed in triplicate. The adherence capabilities of the tested strains were classified into 4 categories; 3 standard deviations (SDs) above the mean OD of the negative control (broth only) was considered as the optical density cutoff (ODc). Isolates were classified as follows: OD $\leq$ ODc non-adherent bacteria; ODc $<$ OD $\leq 2 \times$ ODc, weakly adherent bacteria; $2 \times$ ODc $<$ OD $\leq 4 \times$ ODc, moderately adherent bacteria; $4 \times \mathrm{ODc}<\mathrm{OD}$, strongly adherent bacteria (15).

\subsection{Pulsed-Field Gel Electrophoresis}

The collected isolates were analyzed by PFGE as described by Durmaz et al. (16). Acinetobacter baumannii ATCC 19606 was included for external reference. Genomic DNA was digested with ApaI (New England Biolabs). The lambda ladder PFGE marker (NEB, US) was used as a molecular size marker. The pulsed-field electrophoresis (Chef Mapper; Bio-Rad Laboratories, Hercules, CA, USA) was performed under the following conditions: temperature $14^{\circ} \mathrm{C}$; voltage $6 \mathrm{~V} / \mathrm{cm}$; switch angle, $120^{\circ} \mathrm{C}$; switch ramp 2.2 - 35 seconds for 19 hours. Gels were stained with ethidium bromide and patterns were visualized under UV light (BIO-RAD, USA). DNA banding patterns were analyzed using Bionumeric 7.0 software (Apllied maths NV, St-Martens-Latem Belgium).

\subsection{PCR-Based Sequence Group Typing}

Multiplex PCRs to identify groups (international clone) 1 to 3 organisms were performed by amplification of the ompA, csuE, and $b l a_{O X A-51-l i k e}$ genes using the primers listed in Table 1 (TAG Copenhagenard, Denmark).

PCR were performed under the following conditions: $94^{\circ} \mathrm{C}$ for 3 minutes, then, 30 cycles of $94^{\circ} \mathrm{C}$ for 45 seconds, $57^{\circ} \mathrm{C}$ for 45 seconds and $72^{\circ} \mathrm{C}$ for 1 minute, followed by a final extension at $72^{\circ} \mathrm{C}$ for 5 minutes. Identification of a strain as a member of group 1 or 2 required the amplification of all 3 fragments in the corresponding multiplex PCR, 
Table 1. Primers Used for Multiplex Polymerase Chain Reaction

\begin{tabular}{|c|c|c|}
\hline Prime & Sequence & Size (bp) \\
\hline SIM-F & 5’ - GTACAAGGGATTCGGCATCG-3 & \multirow{2}{*}{569} \\
\hline SIM-R & 5' - GTACAAGGGATTCGGCATCG-3 & \\
\hline NDMI-F & 5' - GAGATTGCCGAGCGACTTG-3 & \multirow{2}{*}{497} \\
\hline NDMI-R & 5' - CGAATGTCTGGCAGCACACTT-3 & \\
\hline Oxa-51-like-F & 5' - TAATGCTTTGATCGGCCTTG-3 & \multirow{2}{*}{353} \\
\hline Oxa-51-like-R & 5' - TGGATTGCACTTCATCTTGG-3 & \\
\hline Oxa-23-like-F & 5' - GATCGGATTGGAGAACCAGA-3 & \multirow{2}{*}{501} \\
\hline Oxa-23-like-R & 5' - ATTTCTGACCGCATTTCCAT-3 & \\
\hline Oxa-24-like-F & 5' - GGTTAGTTGGCCCCCTTAAA-3 & \multirow{2}{*}{246} \\
\hline Oxa-24-like-R & 5' - AGTTGAGCGAAAAGGGGATT-3 & \\
\hline Oxa-58-like-F & 5' - AGTATTGGGGCTTGTGCTG-3 & \multirow{2}{*}{599} \\
\hline Oxa-58-like-R & 5'- ССССТCTGCGCTCTACATAC-3 & \\
\hline Imp-F & 5'- GAATAGAATGGTTAACTCTC-3 & \multirow{2}{*}{188} \\
\hline Imp-R & 5'-CCAAACCACTAGGTTATC-3 & \\
\hline Vim-F & 5' - GTTTGGTCGCATATCGCAAC -3 & \multirow{2}{*}{382} \\
\hline Vim-R & 5'-AATGCGCAGCACCAGGATAG-3 & \\
\hline \multicolumn{3}{|l|}{ Group1 alleles } \\
\hline Group1ompAF306 & 5'- GATGGCGTAAATCGTGGTA-3 & \multirow{2}{*}{355} \\
\hline Group1and2ompAR660 & 5' - CAACTTTAGCGATTTCTGG-3 & \\
\hline GroupicsuEF & 5' - CTTTAGCAAACATGACCTACC-3 & \multirow{2}{*}{702} \\
\hline Group1csuER & 5' - TACACCCGGGTTAATCGT-3 & \\
\hline Gp1OXA66F89 & 5' - GCGCTTCAAAATCTGATGTA-3 & \multirow{2}{*}{559} \\
\hline Gp1OXA66R647 & 5' - GCGTATATTTTGTTTCCATTC-3 & \\
\hline \multicolumn{3}{|l|}{ Group2 alleles } \\
\hline Group2omp AF378 & 5' - GACCTTTCTTATCACAACGA-3 & \multirow{2}{*}{343} \\
\hline GrouPland2ompAR660 & 5' - CAACTTTAAGCGATTTCTGC-3 & \\
\hline Group2csuEF & 5' - GGCGAACATGACCTATTT-3 & \multirow{2}{*}{580} \\
\hline Group2csuER & 5' - CTTCATGGCTCGTTGGTT-3 & \\
\hline Gp2OXA69F169 & 5' - CATCAAGGTCAAACTCAA-3 & \multirow{2}{*}{162} \\
\hline Gp2OXA69R330 & 5' - TAGCCTTTTTTCCCCATC-3 & \\
\hline
\end{tabular}

and an absence of any amplification in the other multiplex PCR. Group 3 isolates were defined by the amplification of only the ompA fragment in the group 2 PCR, and the amplification of only the $c s u \mathrm{E}$, and bla $a_{O X A-51-l i k e}$ fragments in the group 1 PCR (17) (Table 1). The PCR products were separated by $1 \%$ agarose gel electrophoresis stained with neutral red (Sigma Aldrich, Germany) and visualized under UV light.

\section{Results}

\subsection{Bacterial Strains}

The Isolates were isolated from different clinical samples and wards of Loghman (No. 1) and Milad (No. 2) hospitals, described in Table 2.

\subsection{Antibiotic Susceptibility Testing}

The disk diffusion susceptibility testing revealed that $100 \%(n=48)$ of the isolates were resistant to piperacillin. 
Table 2. Clinical Samples and Different Wards of Hospital

\begin{tabular}{lccc}
\hline Clinical Samples & Frequency of Samples $(\mathbf{N})$ & Type of Wards & Frequency of Samples (N) \\
\hline Wound & 13 & Intensive care unit & Pediatric \\
\hline Trachea & 24 & Medical \\
\hline Urine & 3 & Surgery \\
Catheter & 2 & Ear, nose and throat \\
\hline Sputum & 3 & Emergency \\
\hline Burn & 2 & \\
\hline Cerebrospinal fluid & 1 & 2 \\
\hline
\end{tabular}

The rate of resistance to carbapenem was 76\% (meropenem $=77 \%$, imipenem $=77 \%$, and doripenem $=75 \%$; among the other tested antibiotics, colistin and polymixin showed the higher rates of antimicrobial activities (isolates were $100 \%$ sensitive) (Table 3 ).

Minimum inhibitory concentration (MIC) result for meropenem ranged 0.5 to $256 \mu \mathrm{g} / \mathrm{mL}$ as follows: 10 isolates were sensitive, 3 isolates intermediate, and 35 isolates showed resistance. On the other hand, MIC results for imipenem ranged 0.5 to $64 \mu \mathrm{g} / \mathrm{mL}: 11$ isolates were sensitive, 4 isolates intermediate, and 33 isolates resistant.

\subsection{Prevalence of Carbapenemase-Encoding Genes}

All 48 isolates were positive for $b l a_{\text {OXA-51-like. The }}$ carbapenemase-encoding gene, bla OXA-23-like, was found in 32 isolates (64\%). bla OXA-40-like $\left(b l a_{\text {OXA-24-like }}\right), b l a_{\text {OXA-58-like, }}$, $b_{\text {Vla }}$-type, and bla $a_{I M P-t y p e}$ were found in $11(22 \%), 1(2 \%), 19$ (38\%), and $5(10 \%)$ isolates, respectively. None of the isolates had positive PCR results for $b l a_{N D M-t y p e}$ and $b l a_{S I M-t y p e}$.

\subsection{Biofilm Formation}

Among 48 isolates examined in the current study, 13 could not produce biofilm, 28 isolates had weak ability to form biofilm, 4 isolates showed moderate ability, and 3 isolates showed strong ability to form biofilm (Table 4).

\subsection{Pulsed-Field Gel Electrophoresis Results}

The PFGE results (Figure 1A) revealed 11 clonal complexes with cut off level $74 \%$, and the most prevalent clonal complexes were $\mathrm{E}, \mathrm{F}$, and $\mathrm{H}$. The clonal complex $\mathrm{E}$ was the most frequent, with 17 clinical isolates. Pulsotype I was sporadic and did not have close genetic similarity with the other groups (Figure 1).

\subsection{PCR-Based Sequence Group Typing}

All strains belonging to the group 1 of clonal complex yielded all 3 fragments in the group 1 PCR and none of the group 2 PCR; while strains belonging to group 2 gave the expected converse results. Twenty-eight isolates belonged to group 1 and 8 isolates belonged to group 2 . None of the isolates belonged to group 3. Twelve isolates could not be typed by this method.

Of the 28 isolates belonging to group 1, eighteen isolates had bla $_{\text {OXA-23-like }}$ gene, five isolates had bla $_{\text {OXA-23-like }}+$, VIM+ pattern. The pattern of imipenem resistance among the 28 isolates that belonged to group 1 was as follows: 20 isolates were resistant, 3 isolates had intermediate resistance, and 5 were sensitive; for meropenem: 20 isolates showed resistance, 2 isolates showed intermediate resistance, and 6 isolates were sensitive; for doripenem: 19 isolates were resistant, 2 isolates had intermediate resistance, and 7 isolates were sensitive. Of the 8 isolates that belonged to group 2, according to PCR-based sequence group method, 6 isolates had bla OXA-23-like gene, 3 isolates had $b_{\text {OXA-23-like }}+$, VIM+ pattern and 1 isolate did not have resistance genes except for $b_{\text {OXA-51-like }}$; the pattern of resistance for all of the 3 evaluated antibiotics was the same in this group. Seven isolates were resistant to all antibiotics and 1 isolate had intermediate resistance (Tables 5 and 6 ).

\section{Discussion}

Acinetobacter baumannii is one of the main causes of nosocomial infections in the recent years (18). Acinetobacter baumannii is one of the most problematic organisms currently responsible for nosocomial infections, especially in intensive care units (ICUs) (19). Increasing antimicrobial resistance (20) and the ability of $A$. baumannii to survive on inanimate and dry surfaces are linked to the occurrence of periodic outbreaks observed in various hospitals (21). Acinetobacter baumannii is the most common isolate obtained from skin, blood, sputum, pleural fluid, and 
Table 3. Resistance of Acinetobacter baumannii Isolates to the Tested Antibiotics

\begin{tabular}{|c|c|c|c|}
\hline Antibiotic & Resistant, N (\%) & Intermediate, $\mathrm{N}(\%)$ & Susceptible, N(\%) \\
\hline Amikacin & $33(69)$ & $0(0)$ & $15(31)$ \\
\hline Gentamicin & $35(73)$ & $3(6)$ & $10(21)$ \\
\hline Trimethoprim-sulfamethoxazole & $42(88)$ & $2(4)$ & $4(8)$ \\
\hline Ciprofloxacin & $44(92)$ & $0(0)$ & $4(8)$ \\
\hline Ceftazidime & $44(92)$ & $0(0)$ & $4(8)$ \\
\hline Cefepime & $40(84)$ & $4(8)$ & $4(8)$ \\
\hline Cefotaxime & $44(92)$ & $3(6)$ & $1(2)$ \\
\hline Colistin & $0(0)$ & $0(0)$ & $48(100)$ \\
\hline Polymyxin B & $0(0)$ & $0(0)$ & $48(100)$ \\
\hline Piperacillin-tazobactam & $38(79)$ & $0(0)$ & $10(21)$ \\
\hline Piperacillin & $48(100)$ & $0(0)$ & $0(0)$ \\
\hline Minocycline & $4(8)$ & $12(25)$ & $32(67)$ \\
\hline Doxycycline & $27(56)$ & $1(2)$ & $20(42)$ \\
\hline Meropenem & $37(77)$ & $4(8)$ & $7(15)$ \\
\hline Imipenem & $37(77)$ & $5(10)$ & $6(13)$ \\
\hline Doripenem & $36(75)$ & $4(8)$ & $8(17)$ \\
\hline
\end{tabular}

Table 4. Resistance of Acinetobacter baumannii Isolates to carbapenems, Based on the Ability to Form Biofilm

\begin{tabular}{|c|c|c|c|c|c|}
\hline Antibiotic & $\begin{array}{c}\text { Non-Biofilm, Forming }(\mathrm{N}= \\
\text { 13), } \mathrm{N}(\%)\end{array}$ & $\begin{array}{c}\text { Weak Biofilm Forming ( } \mathrm{N} \\
=28), \mathrm{N}(\%)\end{array}$ & $\begin{array}{l}\text { Moderate Biofilm } \\
\text { Forming }(\mathrm{N}=4), \mathrm{N}(\%)\end{array}$ & $\begin{array}{l}\text { Strong Biofilm Forming } \\
\qquad(\mathrm{N}=3), \mathrm{N}(\%)\end{array}$ & Total, N(\%) \\
\hline \multicolumn{6}{|l|}{ Doripenem } \\
\hline Resistant & $8(22.2)$ & $23(63.9)$ & $2(5.6)$ & $3(8.3)$ & $36(100)$ \\
\hline Intermediate & $1(25)$ & $2(50)$ & $1(25)$ & $0(0)$ & $4(100)$ \\
\hline Susceptible & $4(50)$ & $3(37.5)$ & $1(12.5)$ & $0(0)$ & $8(100)$ \\
\hline \multicolumn{6}{|l|}{ Imipenem } \\
\hline Resistant & $10(27)$ & $22(59.5)$ & $2(5.4)$ & $3(8.1)$ & $37(100)$ \\
\hline Intermediate & $1(20)$ & $3(60)$ & $1(20)$ & $0(0)$ & $5(100)$ \\
\hline Susceptible & $2(33.3)$ & $3(50)$ & $1(16.7)$ & $0(0)$ & $6(100)$ \\
\hline \multicolumn{6}{|l|}{ Meropenem } \\
\hline Intermediate & $2(50)$ & $1(25)$ & $1(25)$ & $0(25)$ & $4(100)$ \\
\hline Susceptible & $2(28.6)$ & $4(57.1)$ & $1(14.3)$ & $0(0)$ & $7(100)$ \\
\hline
\end{tabular}

urine (22). As many studies show, the organism is most frequently isolated from the respiratory tract than the other body organs among the ICU admitted patients $(23,24)$.

Acinetobacter baumannii is one of the most frequent causes of nosocomial infections throughout Tehran hospitals, especially in the ICU wards (23). Carbapenem resistance is recently increased by this bacterium; therefore, the current study evaluated the antibiotic sensitiv- ity pattern, carbapenem resistance genes, the ability of biofilm formation, the genetic relationships and the lineages of the species isolated from Tehran hospitals. Most of the samples of the current study were obtained from the ICU wards. The samples were also collected from other wards in high abundance such as medical, surgery, emergency, ear, nose and throat (ENT), and pediatric. Although carbapenems, aminoglycosides, and fluoroquinolones are 


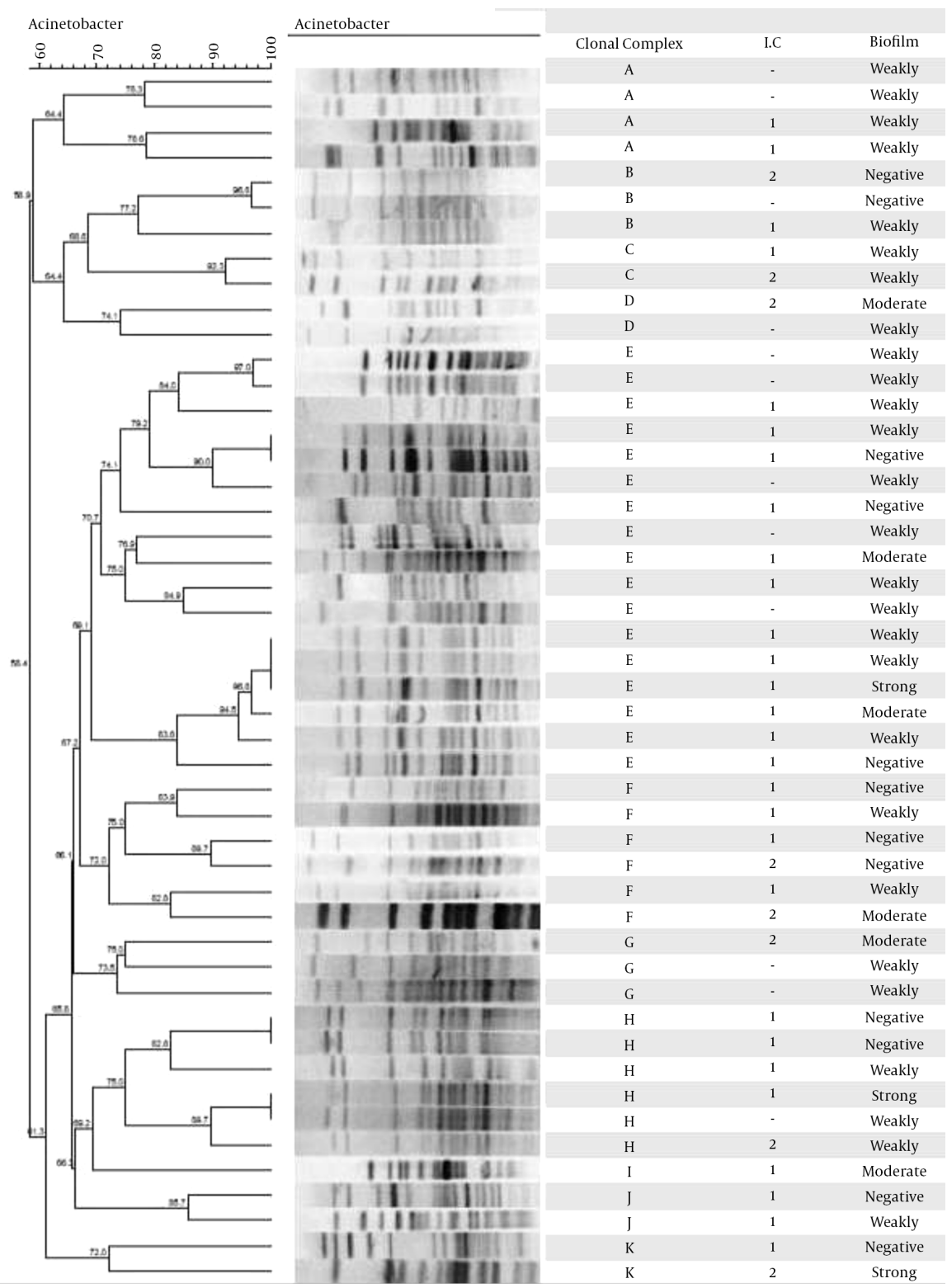

Figure 1. PFGE Clustering Analysis with Cut off Level 74\% of 48 A. baumannii Strains, International Clones, and Biofilm Formation

used to treat A. baumannii infections in different medical settings, resistance to carbapenems is increasing in Iran (25-27).

A worldwide collection of 5127 Acinetobacter spp., collected from 2005 to 2009 from 140 hospitals of 32 countries in North America (17.1\%), Europe (22.9\%), Latin America (25.2\%) and the Asia-Pacific region (34.8\%) showed that overall non-susceptibility rate to imipenem and meropenem was $45.9 \%$ and $48.2 \%$, respectively. However, the nonsusceptibility percentage for imipenem and meropenem, increased from $27.8 \%$ and $37.5 \%$ in 2005 to $62.4 \%$ and $64.4 \%$ in 2009, respectively (28).

From 2008 to 2016, thirty-nine studies were performed in Iran on the antibiotic resistance of A. baumannii that more than half of them were performed in Tehran. Nowadays, the rate of carbapenem resistance has increased in Iran. By definition, MDR A. baumannii isolates are resistant to 3 or more agents of different antibiotic classes. In total, 7 studies revealed the presence of MDR isolates. Among the 7 studies, the rates of MDR ranged from 32.7\% to 93\% in the 
Table 5. Resistance of Acinetobacter baumannii Isolates to the Tested Antibiotics, Based on International Clones and Beta-Lactamase Genes

\begin{tabular}{|c|c|c|c|c|c|c|c|c|}
\hline Antibiotic & $\begin{array}{c}\text { International Clone } \\
1(N=28), N(\%)\end{array}$ & $\begin{array}{c}\text { International Clone } \\
2(\mathrm{~N}=\mathbf{8}), \mathrm{N}(\%)\end{array}$ & $\begin{array}{l}\text { Other International } \\
\text { Clones }(\mathrm{N}=12), \mathrm{N}(\%)\end{array}$ & Total, N (\%) & Bla-oxA23-like & Bla-oxA24-like & VIM & IMP \\
\hline \multicolumn{9}{|l|}{ Doripenem } \\
\hline Resistant & $19(52.8)$ & $7(19.4)$ & $10(27.8)$ & $36(100)$ & 27 & 6 & 16 & 4 \\
\hline Intermediate & $2(50)$ & $1(25)$ & $1(25)$ & $4(100)$ & 2 & 1 & 0 & 1 \\
\hline Susceptible & $7(87.5)$ & $0(0)$ & $1(12.5)$ & $8(100)$ & 3 & 4 & 3 & - \\
\hline Total & & & & & 32 & 11 & 19 & 5 \\
\hline \multicolumn{9}{|l|}{ Imipenem } \\
\hline Resistant & $20(54.1)$ & $7(18.9)$ & $10(27)$ & $37(100)$ & 26 & 8 & 16 & 5 \\
\hline Intermediate & $3(60)$ & $1(20)$ & $1(20)$ & $5(100)$ & 2 & 2 & 2 & - \\
\hline Susceptible & $5(83.3)$ & $0(0)$ & $1(16.7)$ & $6(100)$ & 4 & 1 & 1 & - \\
\hline Total & & & & & 32 & 11 & 19 & 5 \\
\hline \multicolumn{9}{|l|}{ Meropenem } \\
\hline Resistant & $20(54.1)$ & $7(18.9)$ & $10(27)$ & $37(100)$ & 26 & 6 & 16 & 5 \\
\hline Intermediate & $2(50)$ & $1(25)$ & $1(25)$ & $4(100)$ & 3 & 2 & 1 & - \\
\hline Susceptible & $6(85.7)$ & $0(0)$ & $1(14.3)$ & $7(100)$ & 3 & 3 & 2 & - \\
\hline Total & & & & & 32 & 11 & 19 & 5 \\
\hline
\end{tabular}

Table 6. Frequency of Acinetobacter baumannii Isolates in International Clones

\begin{tabular}{|c|c|c|c|c|}
\hline Clonal Complex & International Clone $1(\mathbf{N}=\mathbf{2 8})$ & International Clone $2(\mathrm{~N}=\mathbf{8})$ & Other International Clones $(\mathrm{N}=\mathbf{1 2})$ & Total N \\
\hline $\mathbf{A}$ & 2 & 0 & 2 & 4 \\
\hline B & 1 & 1 & 1 & 3 \\
\hline C & 1 & 1 & 0 & 2 \\
\hline D & 0 & 1 & 1 & 2 \\
\hline $\mathbf{E}$ & 12 & 0 & 5 & 17 \\
\hline $\mathbf{F}$ & 4 & 2 & 0 & 6 \\
\hline G & 0 & 1 & 2 & 3 \\
\hline $\mathbf{H}$ & 4 & 1 & 1 & 6 \\
\hline I & 1 & 0 & 0 & 1 \\
\hline $\mathbf{J}$ & 2 & 0 & 0 & 2 \\
\hline \multirow[t]{2}{*}{$\mathbf{K}$} & 1 & 1 & 0 & 2 \\
\hline & 28 & 8 & 12 & 48 \\
\hline
\end{tabular}

584 isolated A. baumannii species sort by time: 2001 to 2007 (1 study, 50\%), 2008 to 2009 (1 study, 66\%), 2009 to 2010 (1 study, 83\%), and 2010 to 2011 (4 studies, 32.7\%, 74.9\%, 93\%, 94.4\%)(29).

In a study by Karmostaji et al., in Iran during 2012, on 84 isolates of A. baumannii, 50 (59.52\%) species were resistant to imipenem and 74 (88.09\%) were resistant to meropenem (30). Also In another study by karmostaji et al., $54.47 \%$ of the isolates were resistant to amikacin,
$67.47 \%$ to imipenem, and $84.55 \%$ of the isolates were resistant to meropenem. Among the 123 isolates, 100 (81.3 \%) had an acquired bla $a_{\text {OXA-23-like }}$ carbapenemase, 10 (8.1\%) possessed bla $a_{\text {OXA-24-like, }}$ and 1 (0.81\%) bla $a_{\text {OXA-58-like }}$ carbapenemase (31). The results of the current study showed that the carbapenemase-encoding gene, bla $a_{\text {OXA-23-like, }}$, was found in $32(64 \%)$ isolates and this finding was consistent with those of other studies reported from Iran. The bla $a_{\text {OXA-40-like }}$ (bla $\left.a_{\text {OXA-24-like }}\right)$, bla $a_{\text {OXA-58-like }}$, bla $a_{\text {VIM-type, }}$ and bla $_{\text {IMP-type }}$ genes 
were found in $11(22 \%), 1(2 \%), 19(38 \%)$ and $5(10 \%)$ isolates, respectively. However, none of the isolates had positive PCR results for $b l a_{\text {NDM-type }}$ and $b l a_{S I M-t y p e}(29)$. The current study tried to evaluate the results of clonal lineage method with the results obtained by PFGE. In type E, which was the most frequent type in the current study, there were 17 isolates, 13 collected from ICU and 4 from other wards. All 17 isolates were collected in hospital No.1. The origin of 8 isolates was trachea, 5 isolates from wound, 2 isolates from sputum, 1 isolate from urine, and 1 isolate from catheter. Using clonal lineages as a typing method, it was shown that 12 isolates belonged to the group 1 and the method was unable to type 5 other isolates.

Three out of 48 isolates were strong biofilm producers, among which 1 isolate was from hospital No.1 and the other 2 from hospital No.2. Two of these isolates were collected from catheter in ICU and the others were from burn and general wards. These isolates belonged to 3 clonal complexes $\mathrm{E}, \mathrm{H}$, and $\mathrm{K}$ and by PCR-based sequence group typing method it was found that 2 isolates belonged to group 1 and the other belonged to group 2. All 3 isolates showed high resistance to carbapenem; therefore, MIC of these isolates for imipenem and meropenem were 32 to $128 \mu \mathrm{g} / \mathrm{mL}$, respectively. All the isolates were MDR. Isolate 3 , despite harboring just bla OXA-51-like (carbapenem resistance genes), showed high antibiotic resistance to all 3 antibiotics including meropenem, imipenem, and doripenem. None of the isolates had $b l a_{O X A-58-l i k e}$ and $b_{1} a_{I M P-t y p e}$.

All 3 isolates, which were strong biofilm producers, showed resistance to all studied antibiotics. In a similar study conducted by Mahdian et al., 49\% of isolates belonged to international clone 1 and $49 \%$ to international clone 2; also $74 \%$ and $49 \%$ of the isolates harbored bla OXA-23-like $_{\text {and }}$ bla OXA-24-like, respectively; and $75 \%$ and $66 \%$ of the isolates were resistant to the imipenem and meropenem, respectively (27). In another study, 58\% and $29 \%$ of the isolates belonged to international clones 2 and 1 , respectively (32). In the study conducted by Kaliterena et al., in Croatia, 51\% of the A. baumannii species belonged to class 1 and $27 \%$ to class 2 international clone, and the others belonged to other clones (33).

Despite the simplicity and cost-effectiveness of PCRbased sequence group typing method, it could not type all the isolates. However, PFGE as a method can type all isolates.

\subsection{Conclusions}

International clone 2 was the most commonly detected clonal lineage in the current study. Isolates that belonged to this clone were mostly associated with bla $a_{O X A-23-l i k e}$ gene; therefore, $64 \%$ of the isolates in this clone possessed bla $a_{\text {XXA-23-like }}$ gene.

\section{Acknowledgments}

The current study was supported by grants from the faculty of medical sciences, Tarbiat Modares university, Tehran, Iran (ID; 91356) and the Iranian national sciences foundation, Tehran, Iran (ID; 90000066).

\section{Footnotes}

Authors' Contribution: Study concept and design: Shahin Najar-Peerayeh, Mehrdad Behmanesh, and Morovat Taherikalani; acquisition, analysis, and interpretation of data: Mahdi Akbari Dehbalaei, Shahin NajarPeerayeh, and Morovat Taherikalani; drafting of the manuscript: Mahdi Akbari Dehbalaei; critical revision of the manuscript for important intellectual content: Mahdi Akbari Dehbalaei and Shahin Najar-Peerayeh.

Conflict of Interest: Authors declared no conflict of interest.

Financial Disclosure: There was no financial interest related to the material in the manuscript.

\section{References}

1. Peleg AY, Seifert H, Paterson DL. Acinetobacter baumannii: emergence of a successful pathogen. Clin Microbiol Rev. 2008;21(3):538-82. doi: 10.1128/CMR.00058-07. [PubMed:18625687].

2. Seifert H, Schulze A, Baginski R, Pulverer G. Comparison of four different methods for epidemiologic typing of Acinetobacter baumannii.J Clin Microbiol. 1994;32(7):1816-9. [PubMed: 7929781].

3. Hartstein AI, Morthland VH, Rourke JW, Freeman J, Garber S, Sykes $\mathrm{R}$, et al. Plasmid DNA fingerprinting of Acinetobacter calcoaceticus subspecies anitratus from intubated and mechanically ventilated patients. Infect Control Hosp Epidemiol. 1990;11(10):531-8. [PubMed: 2230042].

4. Seifert H, Baginski R, Schulze A, Pulverer G. Antimicrobial susceptibility of Acinetobacter species. Antimicrob Agents Chemother. 1993;37(4):750-3. [PubMed: 8494371].

5. Maragakis LL, Perl TM. Acinetobacter baumannii: epidemiology, antimicrobial resistance, and treatment options. Clin Infect Dis. 2008;46(8):1254-63. doi: 10.1086/529198. [PubMed: 18444865].

6. Zarrilli R, Giannouli M, Tomasone F, Triassi M, Tsakris A. Carbapenem resistance in Acinetobacter baumannii: the molecular epidemic features of an emerging problem in health care facilities. J Infect Dev Ctries. 2009;3(5):335-41. [PubMed: 19759502].

7. Lin MF, Lan CY. Antimicrobial resistance in Acinetobacter baumannii: From bench to bedside. World J Clin Cases. 2014;2(12):787-814. doi: 10.12998/wjcc.v2.i12.787. [PubMed: 25516853].

8. Villalon P, Valdezate S, Medina-Pascual MJ, Rubio V, Vindel A, SaezNieto JA. Clonal diversity of nosocomial epidemic Acinetobacter baumannii strains isolated in Spain. J Clin Microbiol. 2011;49(3):875-82. doi: 10.1128/JCM.01026-10. [PubMed: 21177889].

9. Da Silva G, Dijkshoorn L, van der Reijden T, van Strijen B, Duarte A. Identification of widespread, closely related Acinetobacter baumannii isolates in Portugal as a subgroup of European clone II. Clin Microbiol Infect. 2007;13(2):190-5. doi: 10.1111/j.1469-0691.2006.01628.x. [PubMed: 17328732]. 
10. Di Popolo A, Giannouli M, Triassi M, Brisse S, Zarrilli R. Molecular epidemiological investigation of multidrug-resistant Acinetobacter baumannii strains in four Mediterranean countries with a multilocus sequence typing scheme. Clin Microbiol Infect. 2011;17(2):197-201. doi: 10.1111/j.1469-0691.2010.03254.x. [PubMed: 20456455].

11. Giannouli M, Cuccurullo S, Crivaro V, Di Popolo A, Bernardo M, Tomasone $\mathrm{F}$, et al. Molecular epidemiology of multidrug-resistant Acinetobacter baumannii in a tertiary care hospital in Naples, Italy, shows the emergence of a novel epidemic clone. JClin Microbiol. 2010;48(4):122330. doi: 10.1128/JCM.02263-09. [PubMed: 20181918].

12. Turton JF, Woodford N, Glover J, Yarde S, Kaufmann ME, Pitt TL. Identification of Acinetobacter baumannii by detection of the blaOXA51-like carbapenemase gene intrinsic to this species. J Clin Microbiol. 2006;44(8):2974-6. doi:10.1128/JCM.01021-06. [PubMed: 16891520].

13. Patel J, Cockerill F, Alder J, Bradford P, Eliopoulos G, Hardy D. Performance standards for antimicrobial susceptibility testing; twentyfourth informational supplement. 34. CLSI standards for antimicrobial susceptibility testing.; 2014.

14. Abdalhamid B, Hassan H, Itbaileh A, Shorman M. Characterization of carbapenem-resistant Acinetobacter baumannii clinical isolates in a tertiary care hospital in Saudi Arabia. New Microbiol. 2014;37(1):65-73. [PubMed: 24531172].

15. Badmasti F, Siadat SD, Bouzari S, Ajdary S, Shahcheraghi F. Molecular detection of genes related to biofilm formation in multidrugresistant Acinetobacter baumannii isolated from clinical settings. J Med Microbiol. 2015;64(Pt 5):559-64. doi: 10.1099/jmm.0.000058. [PubMed: 25813817].

16. Durmaz R, Otlu B, Koksal F, Hosoglu S, Ozturk R, Ersoy Y, et al. The optimization of a rapid pulsed-field gel electrophoresis protocol for the typing of Acinetobacter baumannii, Escherichia coli and Klebsiella spp.Jpn J Infect Dis. 2009;62(5):372-7. [PubMed: 19762987].

17. Turton JF, Gabriel SN, Valderrey C, Kaufmann ME, Pitt TL. Use of sequence-based typing and multiplex PCR to identify clonal lineages of outbreak strains of Acinetobacter baumannii. Clin Microbiol Infect. 2007;13(8):807-15. doi: 10.1111/j.1469-0691.2007.01759.x. [PubMed: 17610600].

18. Anvarinejad M, Japoni A, Davarpanah MA, Mahmudi H, Mammina C, Vazin A. Phenotypic and Molecular Epidemiology of Acinetobacter calcoaceticus baumannii Complex Strains Spread at Nemazee Hospital of Shiraz, Iran. Jundishapur J Microbiol. 2015;8(6):19180. doi: 10.5812/jjm.8(5)2015.19180. [PubMed: 26322204].

19. Falagas ME, Karveli EA. The changing global epidemiology of Acinetobacter baumannii infections: a development with major public health implications. Clin Microbiol Infect. 2007;13(2):117-9. doi: 10.1111/j.1469-0691.2006.01596.x. [PubMed: 17328722].

20. Van Looveren M, Goossens H, Arpac Steering Group . Antimicrobial resistance of Acinetobacter spp. in Europe. Clin Microbiol Infect. 2004;10(8):684-704. doi: 10.1111/j.1469-0691.2004.00942.x. [PubMed: 15301671].

21. Hamouda A, Evans BA, Towner KJ, Amyes SG. Characterization of epidemiologically unrelated Acinetobacter baumannii isolates from four continents by use of multilocus sequence typing, pulsed-field gel electrophoresis, and sequence-based typing of bla(OXA-51-like) genes. J Clin Microbiol. 2010;48(7):2476-83. doi: 10.1128/JCM.02431-09. [PubMed: 20421437].
22. Shelburne S3, Singh KV, White AC, Byrne L, Carmer A, Austin C, et al. Sequential outbreaks of infections by distinct Acinetobacter baumannii strains in a public teaching hospital in Houston, Texas. J Clin Microbiol. 2008;46(1):198-205. doi: 10.1128/JCM.01459-07. [PubMed: 18003801].

23. Mohajeri P, Farahani A, Feizabadi MM, Ketabi H, Abiri R, Najafi F. Antimicrobial susceptibility profiling and genomic diversity of Acinetobacter baumannii isolates: A study in western Iran. Iran J Microbiol. 2013;5(3):195-202. [PubMed: 24475323].

24. Shahcheraghi F, Abbasalipour M, Feizabadi M, Ebrahimipour G, Akbari N. Isolation and genetic characterization of metallo-betalactamase and carbapenamase producing strains of Acinetobacter baumannii from patients at Tehran hospitals. Iran J Microbiol. 2011;3(2):68-74. [PubMed: 22347585].

25. Najar Peerayeh S, Karmostaji A. Molecular Identification of Resistance Determinants, Integrons and Genetic Relatedness of Extensively Drug Resistant Acinetobacter baumannii Isolated From Hospitals in Tehran, Iran. Jundishapur J Microbiol. 2015;8(7):27021. doi: 10.5812/jjm.27021v2. [PubMed: 26421140].

26. Bahador A, Taheri M, Pourakbari B, Hashemizadeh Z, Rostami $\mathrm{H}$, Mansoori N, et al. Emergence of rifampicin, tigecycline, and colistin-resistant Acinetobacter baumannii in Iran; spreading of MDR strains of novel International Clone variants. Microb Drug Resist. 2013;19(5):397-406. doi: 10.1089/mdr.2012.0233. [PubMed: 23768166].

27. Mahdian S, Sadeghifard N, Pakzad I, Ghanbari F, Soroush S, Azimi L, et al. Acinetobacter baumannii clonal lineages I and II harboring different carbapenem-hydrolyzing-beta-lactamase genes are widespread among hospitalized burn patients in Tehran. J Infect Public Health. 2015;8(6):533-42. doi: 10.1016/j.jiph.2015.04.030. [PubMed: 26111484].

28. Mendes RE, Farrell DJ, Sader HS, Jones RN. Comprehensive assessment of tigecycline activity tested against a worldwide collection of Acinetobacter spp. (2005-2009). Diagn Microbiol Infect Dis. 2010;68(3):30711. doi: 10.1016/j.diagmicrobio.2010.07.003. [PubMed: 20955916].

29. Moradi J, Hashemi FB, Bahador A. Antibiotic Resistance of Acinetobacter baumannii in Iran: A Systemic Review of the Published Literature. Osong Public Health Res Perspect. 2015;6(2):79-86. doi: 10.1016/j.phrp.2014.12.006. [PubMed: 25938016].

30. Karmostaj A, Najar-Peerayeh S, Salmanian AH. Emergence of tigecycline resistant Acinetobacter baumannii from an intensive care unit (ICU) in Tehran. Jundishapur J Microbiol. 2013;6(3):215-9. doi: $10.5812 / \mathrm{jjm} .4710$.

31. Karmostaji A, Najar-Peerayeh S, Salmanian AH. Distribution of OXAtype class $\mathrm{D} \beta$-lactamase genes among nosocomial multi drug resistant Acinetobacter baumannii isolated in Tehran hospitals. Jundishapur J Microbiol. 2013;6(5):e8219. doi: 10.5812/jjm.8219.

32. Bahador A, Raoo An R, Farshadzadeh Z, Beitollahi L, Khaledi A, Rahimi $\mathrm{S}$, et al. The Prevalence of IS Aba 1 and IS Aba 4 in Acinetobacter baumannii Species of Different International Clone Lineages Among Patients With Burning in Tehran, Iran. Jundishapur J Microbiol. 2015;8(7):17167. doi: 10.5812/jjm.17167v2. [PubMed: 26396712].

33. Kaliterna V, Kaliterna M, Hrenovic J, Barisic Z, Tonkic M, GoicBarisic I. Acinetobacter baumannii in Southern Croatia: clonal lineages, biofilm formation, and resistance patterns. Infect Dis (Lond). 2015;47(12):902-7. doi: 10.3109/23744235.2015.1078906. [PubMed: 26365683]. 